\title{
Microstructural properties, thermal stability and superplasticity of a ZK60 Mg alloy processed by high-pressure torsion
}

\author{
S.A. Torbati-Sarraf ${ }^{1 \dagger}$, S. Sabbaghianrad ${ }^{1}$, T.G. Langdon ${ }^{1,2}$ \\ torbatis@usc.edu \\ ${ }^{1}$ Departments of Aerospace \& Mechanical Engineering and Materials Science, University of Southern California, \\ Los Angeles, CA 90089-1453, U.S.A. \\ ${ }^{2}$ Materials Research Group, Faculty of Engineering and the Environment, University of Southampton, \\ Southampton SO17 1BJ, U.K.
}

\begin{abstract}
An extruded ZK60 magnesium alloy was used to investigate microstructure, hardness and tensile properties after processing by 5 turns of high-pressure torsion (HPT) at room temperature. EBSD results confirmed the successful production of an ultrafine-grained structure with a mean grain size of $\sim 700 \mathrm{~nm}$ with reasonable homogeneity and a majority of grains oriented parallel to the shear direction. This material also reached a homogeneous microhardness across the disk with an average hardness value saturated at $\mathrm{Hv} \approx 124$ from the as-received hardness value of $\mathrm{Hv} \approx 74$. The obtained high value is due to a high density of dislocations, the very small grain size and texture strengthening. The microhardness retained homogeneity after annealing samples processed by HPT for 40 hours at $448 \mathrm{~K}$. However, the hardness value dropped to Hv $\approx 85$ while the mean grain size increased to $\sim 2.1 \mu \mathrm{m}$. These changes may be a result of restoration processes and consequent texture softening. Specimens processed by 5 turns of HPT exhibit excellent superplastic properties with a maximum elongation of $940 \%$ at $523 \mathrm{~K}$ and an optimum strain rate of $1.0 \times 10^{-4} \mathrm{~s}^{-1}$. Significant superplasticity was observed at $448 \mathrm{~K}$ due to the stability of the bimodal structure at lower temperatures. This can assist the microstructure to accommodate grain boundary sliding and intragranular slip simultaneously and postpone any necking.
\end{abstract}

Keywords: high-pressure torsion, hardness, magnesium alloy, severe plastic deformation, superplasticity, thermal stability, texture

\section{Мискроструктурные свойства, термическая стабильность и сверхпластичность магниевого сплава ZK60, деформированного кручением под высоким давлением}

Для исследования микроструктуры, твердости и свойств при растяжении после деформации 5 оборотами кручения под высоким давлением (КВД) при комнатной температуре был использован экструдированный сплав магния ZК60. Результаты дифракции обратно рассеянных электронов показывают, что при этом образуется ультрамелкозернистая структура с размером зерен около 700 нм с удовлетворительной однородностью, большинство зерен в которой ориентировано параллельно направлению сдвига. Материал также показывает однородную твердость по площади диска со средним значением микротвердости, которое достигает насыщения при $\mathrm{Hv} \approx 124$ от исходного значения, равного $\mathrm{Hv} \approx 74$. Полученное высокое значение связано с высокой плотностью дислокаций, очень малым размером зерен и текстурным упрочнением. Микротвердость сохранила однородность после отжига образцов после КВД в течение 40 ч при 448 К. Однако значение твердости испытало резкое падение до $\mathrm{Hv} \approx 85$, а средний размер зерен возрос до 2.1 мкм. Эти изменения могут быть следствием процессов возврата и вызванного ими текстурного разупрочнения. Образцы, деформированные до 5 оборотов КВД, проявляют отличные сверхпластические свойства с максимальным удлинением $940 \%$ при $523 \mathrm{~K}$ и оптимальной скоростью деформации $1.0 \times 10^{-4} \mathrm{c}^{-1}$. Значительная сверхпластичность наблюдалась при 448 К благодаря стабильности бимодальной структуры при более низких температурах. Такая микроструктура могла способствовать одновременной аккомодации зернограничного проскальзывания и внутризеренного скольжения и задержке шейкообразования.

Ключевые слова: кручение под высоким давлением, твердость, магниевый сплав, интенсивная пластическая деформация, сверхпластичность, термическая стабильность, текстура 


\section{Introduction}

It has been well established that the grain size is the most important structural parameter affecting the mechanical properties of polycrystalline materials [1]. A small grain size leads to a significantly higher strength through the Hall-Petch relationship in the low-temperature regime $[2,3]$. Additionally, at higher temperatures, small grain sizes give faster strain rates and they enhance the feasibility of superplastic forming for industrial forming processes [4]. Therefore, grain refinement methods have globally absorbed much attentions. Among the various grain refinement methods, severe plastic deformation (SPD) is important because of the possibility to achieve ultrafine-grained (UFG) materials $[5,6]$ through the top-down method.

SPD techniques provide materials with exceptional physicomechanical properties such as abnormally high diffusivity [7,8], a lower elasticity modulus [9], and a sharp decrease in superplastic temperature [10]. Several SPD processing methods have been developed [11] such as equalchannel angular pressing (ECAP) [12] and high-pressure torsion (HPT) [13]. Limited ductility of some materials at room temperature such as $\mathrm{Mg}$ alloys [14] inhibits processing by ECAP at ambient temperature $[15,16]$. However earlier experimental studies $[17,18]$ show that it is possible to process $\mathrm{Mg}$ alloys by HPT at room temperature which leads to both smaller grain sizes and a higher fraction of grain boundaries having high-angles of misorientation than when processing using ECAP [19]. Recent studies have demonstrated an enhancement of the mechanical properties by producing smaller grains with high-angles of misorientation by a combination of ECAP and HPT [20].

Due to the exceptional density of $\mathrm{Mg}$ alloys, the use of these materials is increasing in biomedical [21] and aerospace applications [22] as well as in the automotive industries [23]. However, insufficient formability of $\mathrm{Mg}$ alloys due to the limited availability of slip systems in the hexagonal closepacked crystal structure leads to poor ductilities at room temperature. There are comprehensive studies $[24,25]$ to improve the mechanical properties of these alloys so that they will meet the requirements for automotive, aerospace and biomedical applications

It is well established [26] that plastic deformation of $\mathrm{Mg}$ alloys leads to both grain refinement and the development of crystallographic texture. As a result, an enhancement of mechanical properties and significant anisotropy can be expected. On the other hand, processing by SPD techniques retains the residual stress in the microstructure [27] due to the high magnitude of the applied strain so that grain growth occurs after processing. Therefore, a thermal stability of microstructure during experiments at the testing conditions is essential.

The objective of this research was first to investigate microstructure and the level of grain refinement of a ZK60 $\mathrm{Mg}$ alloy by performing HPT processing at room temperature and to evaluate the thermal stability of processed materials after long-term static annealing. Second, to examine the tensile properties of these HPT-processed materials and to investigate the superplastic behavior at elevated temperatures.

\section{Experimental material and procedures}

In this experiment, a ZK60 Mg alloy with chemical composition of Mg-5.5 wt.\% Zn-0.5 wt.\% Zr was used in a rod shape with diameter of $10 \mathrm{~mm}$. The rods were received after extrusion. Samples were sliced perpendicularly from the rods into disks with thicknesses of $\sim 1.2 \mathrm{~mm}$. By using abrasive papers on both sides, the disks were carefully polished and a series of samples was produced with ultimate thicknesses of $\sim 0.82 \mathrm{~mm}$.

The HPT processing was conducted under quasiconstrained condition [28] using an HPT facility containing a rotating lower anvil. Both the upper and lower anvils contained central spherical depressions with depths of 0.25 $\mathrm{mm}$ and diameters of $10 \mathrm{~mm}$. All processing was carried out at room temperature using an applied pressure, $\mathrm{P}$, of 2.0 $\mathrm{GPa}$ and a constant rotating speed of $1 \mathrm{rpm}$ through a total number, $\mathrm{N}$, of 5 turns. Observations after HPT processing showed no damage, cracking, or slippage after processing by HPT up to 5 revolutions at $2.0 \mathrm{GPa}$.

The thermal stability of the ultrafine-grained structure was examined through static annealing of the samples. Each sample was coated using an alumina spray to inhibit probable oxidation at high temperatures. Samples processed by HPT were annealed at $448 \mathrm{~K}$ using an electrical furnace for 40 hours. The microstructural characteristics of the processed samples were investigated in the mid-radius of the crosssections of the billets. These observations were made on the near surface area of the disks. A JEOL IB09010CP ion beam cross-sectional polishing machine was used to polish the samples at an operating voltage of $6 \mathrm{kV}$ for 5 hours. Electron back-scatter diffraction (EBSD) and orientation imaging microscopy (OIM) were utilized to record these data. An analytical field emission scanning electron microscope (SEM) JEOL JSM-7001F was used at an operating voltage of $7 \mathrm{kV}$. Low-angle grain boundaries (LAGBs) were set in the software as boundaries having misorientation differences between adjacent measuring points of $2^{\circ}-15^{\circ}$ and highangle grain boundaries (HAGBs) were defined as having misorientation differences of more than $15^{\circ}$.

Transmission electron microscopy (TEM) was also utilized to investigate the microstructural characteristics afterprocessing the samples by 5 turns of HPT. Focused ion beam (FIB) was used to prepare the samples for examination. A TEM thin foil was sectioned from the mid-radius area of the disk and specimens were processed by FIB under 20 $\mathrm{kV}$ using gallium ion to a final thickness of $\sim 100 \mathrm{~nm}$. TEM microscopy was performed using a Philips CM12 microscope operating at $200 \mathrm{kV}$ working with a field emission gun.

Microhardness measurements were conducted on samples along randomly selected diameters of the upper surfaces of the disks. All samples were polished to achieve mirror-like surfaces by removing up to a depth of $\sim 0.1 \mathrm{~mm}$ of each surface before taking the measurements. The Vickers microhardness values, $\mathrm{Hv}$, were obtained at room temperature using an FM-1e microhardness instrument equipped with a Vickers indenter using a load of $100 \mathrm{gf}$ with a dwell time of $10 \mathrm{~s}$ for each separate measurement. The indentation points were separated from each other by incremental distances of $0.3 \mathrm{~mm}$. The hardness values were recorded as the average of 
four positions formed in a cross-shape around the selected point at distances of $0.15 \mathrm{~mm}$.

Tensile testing of miniature samples was used to evaluate the mechanical properties of processed samples. Specimens were cut from off-center positions within the HPT disks. Two identical samples were obtained from each of the disks. Electrical discharge machining (EDM) was employed to cut two miniature tensile specimens from each disk. The gauge lengths of the tensile samples were $1.0 \mathrm{~mm}$ with cross-sectional areas of approximately $1.0 \times 0.64 \mathrm{~mm}^{2}$. The specimens were pulled in tension to failure by using an Instron testing machine operating at a constant cross-head displacement rate. Specimens were examined at temperatures of $448,473,523$ and $573 \mathrm{~K}$ and at an initial strain rate of $1.0 \times 10^{-4} \mathrm{~s}^{-1}$. The recorded load-displacement data were converted to engineering stress versus engineering strain. The flow stresses and the elongations to failure were measured from the stress-strain curves.

\section{Experimental results}

Figure 1 shows TEM images of a sample processed by HPT after 5 turns and they reveal an equiaxed ultrafine microstructure. The TEM image of the sample illustrated in Fig. 1a shows a bright field image and an electron diffraction pattern of the processed sample with a mean grain size of $300 \mathrm{~nm}$. The electron diffraction pattern shows a highangle misorientation of neighboring grains. Figure $1 \mathrm{~b}$ shows a dark field image at the same position depicted in Fig. 1a. A considerable increase in the dislocation density inside the grain is observed compared to extruded Mg alloys [29]. For better observation of dislocations inside the grains, a weak beam dark field (WBDF) image was taken from a random-

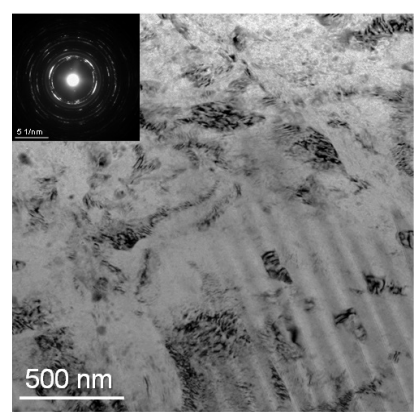

(a)

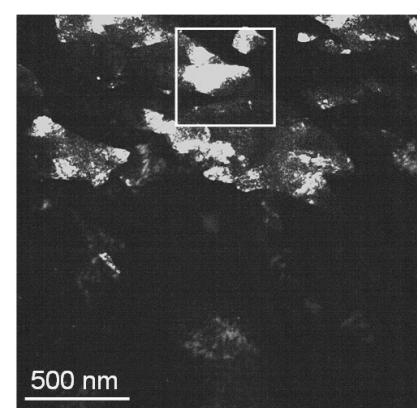

(b)

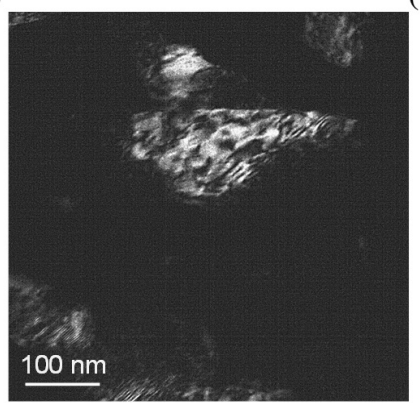

(c)

Fig. 1. TEM images of ZK60 alloy processed by HPT after 5 revolutions: (a) bright field image, (b) conventional dark field image at the same position and (c) weak beam dark field at higher magnification for the grain marked in (b). ly selected and marked area in Fig. $1 \mathrm{~b}$ and this is shown in Fig. 1c. A high density of dislocations is observed.

EBSD images and the grain boundary misorientation distributions for the ZK60 alloy processed by 5 turns of HPT are shown in Fig. 2 before annealing in (a) and after subsequent annealing in (b). The depicted unit triangle with multi-color pattern shows each crystal orientation with a reference color. The colors in the EBSD images are representative of misorientations by referring to the triangle colors. The information of the boundary misorientation distributions is given for HAGBs having misorientation angles, $\theta$, of $\theta>15^{\circ}$ and LAGBs having misorientations of $\theta \approx 2-15^{\circ}$.

An initial measurement of the microstructure of the extruded material showed an average grain size of $\sim 9 \mu \mathrm{m}$. However, the microstructural images of the samples after HPT processing revealed the presence of many highly-refined grains in Fig. 3. A comprehensive study on microstructure and microhardness evolution to reach a reasonable homogeneity for the ZK60 Mg alloy was reported earlier with optical

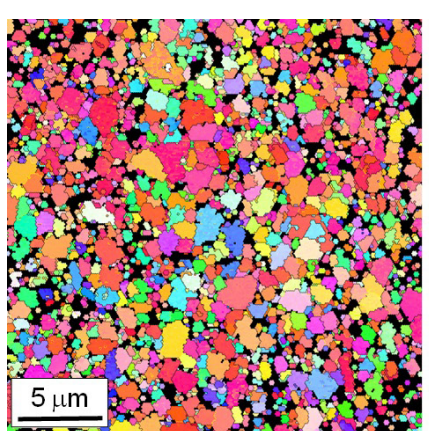

(a)

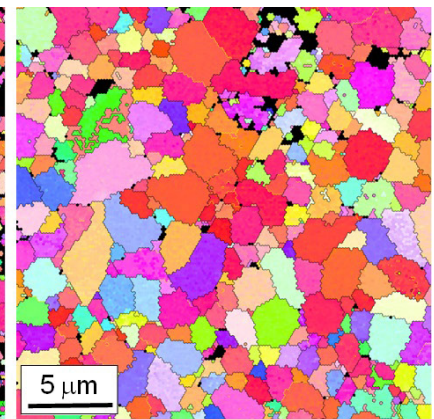

(b)

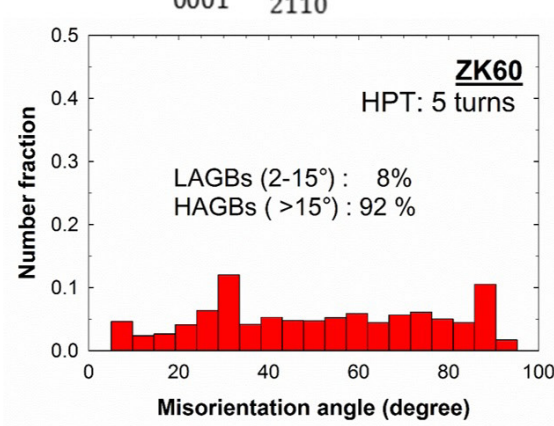

(c)

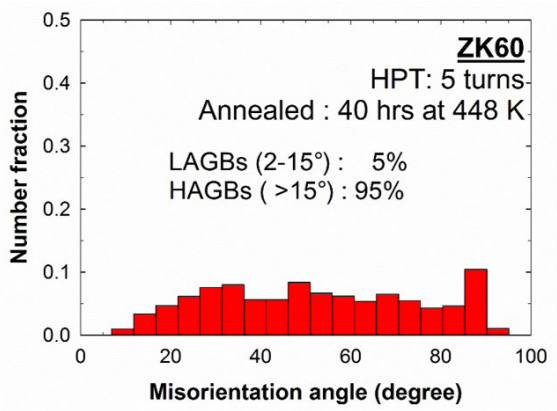

(d)

Fig. 2. EBSD orientation micrographs of (a) ZK60 after 5 turns of HPT and (b) subsequently annealed for 40 hours at $448 \mathrm{~K}$; (c) and (d) corresponding number fractions vs. misorientation angles in the mid-radius of the disks. 


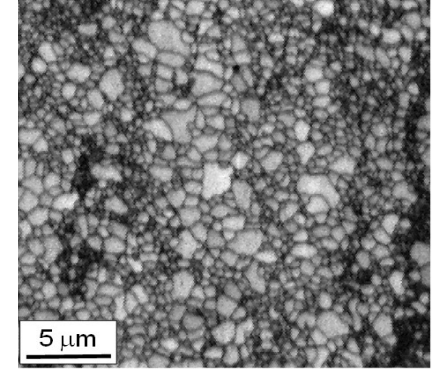

(a)

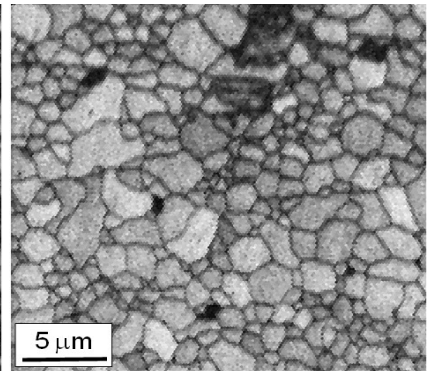

(b)

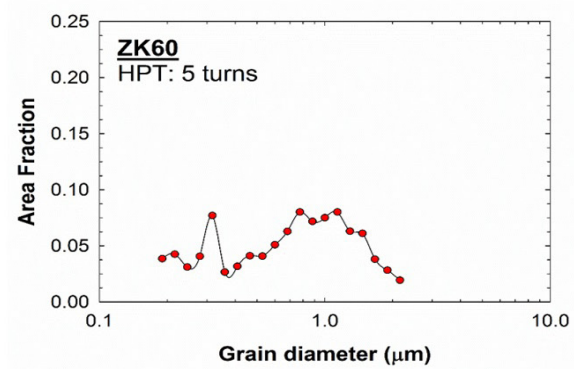

(c)

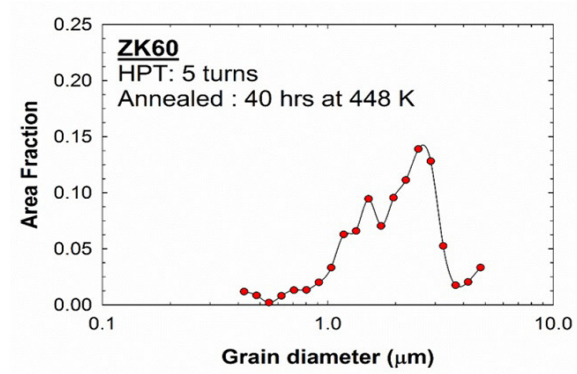

(d)

Fig. 3. EBSD pattern quality micrographs of (a) ZK60 after 5 turns of HPT and (b) subsequently annealed for 40 hours at $448 \mathrm{~K}$; (c) and (d) corresponding grain size distributions in mid-radius of the disks.

micrographs [17]. Figure 3 provides micrographs showing the image quality pattern of microstructures and grain size distributions of the corresponding micrographs for samples processed by HPT in Fig. 3a and (c), respectively. It can be seen that after 5 turns there is an ultrafine-grained structure with bimodal microstructure and a coexistence of two populations of grains with distinctly different average size and morphology. It is suggested that the microstructure is now bimodal with some grains having sizes of $\sim 1.2 \mu$ m lying within arrays of relatively smaller grains with an average grain size of $\sim 250 \mathrm{~nm}$. The overall measured grain size was $\sim 710 \pm 30 \mathrm{~nm}$. The image quality pattern and corresponding grain size distribution are shown for the sample annealed for 40 hours at $448 \mathrm{~K}$ in Fig. $3 \mathrm{~b}$ and (d), respectively. It is apparent that after annealing the specimen, the grain size distribution evolves from bimodal and skewed distribution into a fairly normal distribution and larger grain sizes with an average grain size of $\sim 2.1 \pm 0.1 \mu \mathrm{m}$. This annealing temperature was selected to avoid very rapid grain growth taking place in $\mathrm{Mg}$ alloys at temperatures higher than $473 \mathrm{~K}$ [30]. This increase in the grain size may therefore affect the mechanical properties.

Figure 4 demonstrates the Vickers microhardness, Hv, values taken along randomly selected diameters of disks of

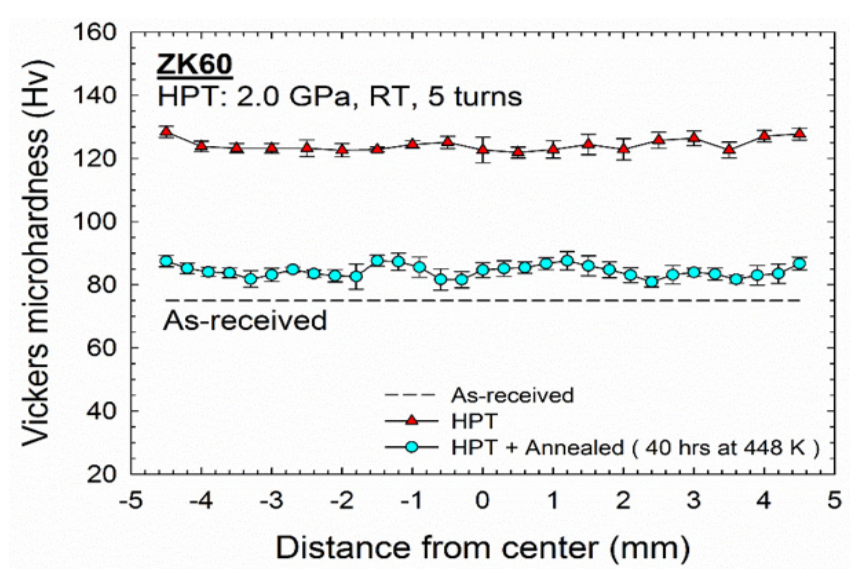

Fig. 4. Vickers microhardness across diameters of disks of the ZK60 alloy processed through 5 turns of HPT and after annealing for 40 hours at $448 \mathrm{~K}$.

the ZK60 alloy at different conditions. The Hv values are plotted against the distance from the center of each disk. The lower dashed line corresponds to the average hardness value measured from the cross-sectional area of the as-received extruded material. After 5 turns of HPT at $2.0 \mathrm{GPa}$, the hardness values are significantly increased and reach $\mathrm{Hv} \approx 124 \pm 2$ with a reasonable homogeneity. After annealing the HPT-processed samples for 40 hours at $448 \mathrm{~K}$, the hardness values stabilized at $\mathrm{Hv} \approx 85 \pm 3$. However, it continued to maintain a homogeneity of hardness across the surface of the processed materials. Homogeneity in hardness is essentially representative of homogeneity of microstructure after annealing and it is vitally important to maintain homogeneity of microstructure for testing materials in tension at high temperatures and low strain rates.

To investigate the mechanical properties of the homogenized ultrafine-grained materials, tensile testing was carried out on samples at temperatures ranging from 448 to $573 \mathrm{~K}$ at an initial strain rate of $1.0 \times 10^{-4} \mathrm{~s}^{-1}$ and the results are shown in Fig. 5. The curves in Fig $5 \mathrm{a}$ are representative of the commonly observed ultrafine-grained material behavior at elevated temperatures with high elongations to failure. Thus, the higher the temperature so the lower the strain hardening and flow stress. Fig. $5 \mathrm{~b}$ depicts the corresponding appearance of the tensile specimens pulled to failure in Fig. 5a where the upper specimen is in an untested condition.

\section{Discussion}

A high dislocation density is observed in many grains, while some grains contain a low dislocation density in Fig 1. Similar evidence of non-equilibrium grain boundaries has been reported for copper and aluminum alloys processed by SPD [31]. However, it was reported that after ECAP of AZ31 at a high temperature [32], most grain boundaries are distinct and well defined. An absence of non-equilibrium grain boundaries in the Mg alloys processed by ECAP is due to its relatively high ECAP temperature. It can be concluded that since there is no immediate transformation of grains to an equilibrium state at a low temperature, some grains with high dislocation densities remain in the microstructure. The 
stability of the grain structure at elevated temperatures was investigated by annealing the HPT-processed samples for long terms ( 40 hours) at a temperature set to the minimum tensile testing temperature of $448 \mathrm{~K}$. This is equivalent to an homologous temperature of $0.49 T_{m}$, where the melting point, $T_{m}$, of ZK60 is $908 \mathrm{~K}$ [33].

The strengthening mechanisms of metals can be classified by dislocation strengthening, precipitation strengthening, solid solution strengthening, and grain boundary strengthening. The first three mechanisms deal with hindering dislocation movement in grains and the last mechanism inhibits extension of plastic deformation in the entire structure. A recent investigation on pure $\mathrm{Mg}$ [34] shows not only grain refinement and dislocation density should be considered but also the texture after HPT plays an important role in hardness of the SPD-processed materials. Since the basal plane is the primary slipping system active in low temperature deformation of $\mathrm{Mg}$ alloys, changes in the basal plane texture is perhaps influential in the mechanical behavior of the alloy. Earlier experiments showed that even after the early stages of HPT a remarkable increase of microhardness took place with respect to the extruded ZK60 alloy where no such extreme grain refinement and high dislocation density has occurred [17]. It can be deducted that the texture strengthening is an important factor in hardening of materials especially in the early levels of processing in which dislocation hardening and grain size play only minor roles. It was also illustrated earlier [35] that in $\mathrm{Mg}$ alloys the majority of basal planes are oriented parallel to the extrusion direction after processing. Inevitably, by applying shear through torsional straining in HPT, the basal planes must rotate by 90 degree to positions parallel to the shear direction. As shown in Fig. 2a, a majority of crystals are oriented parallel to the shear direction after 5 turns of HPT and they obtain a saturated and homogeneous microhardness in Fig. 4. The critical resolved shear stress, CRSS, of non-basal slip in single crystal Mg [36] is two times the magnitude of the basal slip systems at ambient temperature. Considering the point that deformation along the forming direction limits the basal slip, it is beneficial to activate non-basal slip which leads to texture strengthening at room temperature. Therefore texture hardening contributes to the microhardness values obtained at room temperature after processing by HPT.

By annealing the samples for 40 hours at $448 \mathrm{~K}$, it can be seen in Fig. 4 that the microhardness drops considerably from $\mathrm{Hv} \approx 124$ to $\mathrm{Hv} \approx 85$. Generally, by annealing samples at a temperature close to or higher than $0.5 T_{m}$, restoration processes such as recovery, recrystallization, and grain growth are enhanced [37]. It is observed in Fig. $2 b$ and (c) that the fraction of LAGBs decreases to some extent from $8 \%$ to $5 \%$. It is demonstrated in Fig. 1 that limited dynamic recovery takes place during HPT processing. Similar behavior was reported earlier in a Mg10Gd alloy [38] due to observations of an increase in dislocation density by straining the samples. However, TEM observations after processing by HPT of Mg alloys at $423 \mathrm{~K}$ [19] show that the grains are free of dislocations and the microstructures contain grains that are fully separated by boundaries having high angles of misorientation. These measurements and observations confirm that the dislocation density has decreased within the grains by annealing. This af-

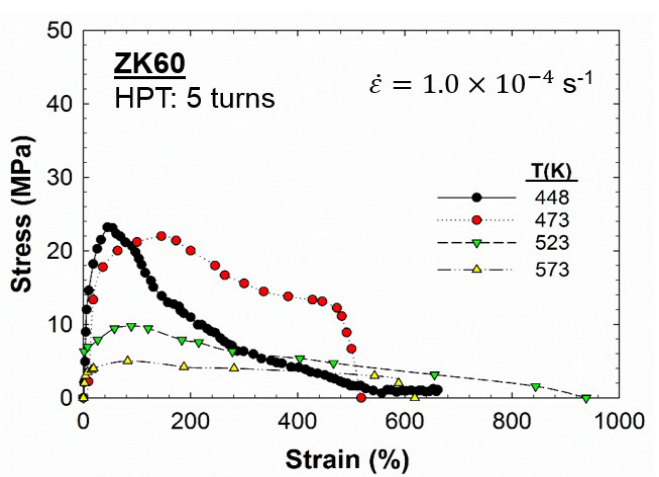

(a)

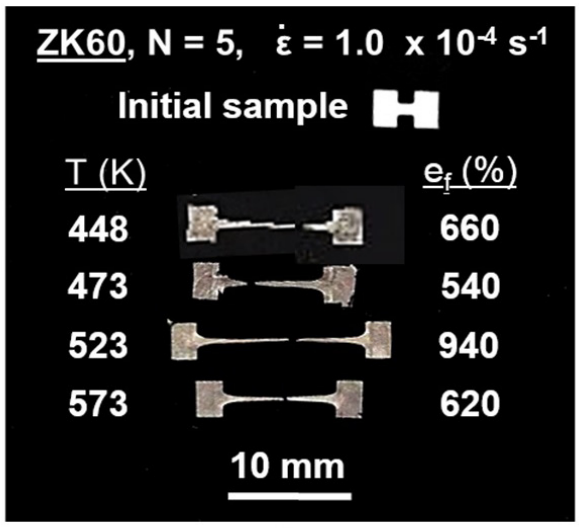

(b)

Fig. 5. (a) Plots of engineering stress-engineering strain of ZK60 alloy pulled in tension to failure at an initial strain rate of $1.0 \times 10^{-4} \mathrm{~s}^{-1}$ for different temperatures at 5 turns and (b) appearance of specimens pulled to failure in (a).

fects the dislocation strengthening mechanism.

After annealing the HPT-processed samples, the grain size changes from $\sim 0.7$ to $\sim 2.1 \mu \mathrm{m}$ and the hardness decreases due to the Hall-Petch effect [32]. However, it is also observed that the saturated hardness after annealing is remarkably close to the hardness of the initial extruded samples with hardness of $\mathrm{Hv} \approx 75$ and grain size of $\sim 9 \mu \mathrm{m}$. This behavior was not seen even after processing Mg alloys by HPT at temperatures lower than $473 \mathrm{~K}$ where no drastic grain growth occurs [30]. Therefore, the other reason for the dramatic drop may lie in a texture softening effect. As shown in Fig. $3 \mathrm{~b}$ and (d), the texture after annealing of HPT-processed samples is relatively closer to the random distribution of misorientations. It is representative of recrystallization where there is nucleation and growth of new grains after an annealing process which may result in a texture softening. There are reports confirming the influence of texture strengthening or softening in different $\mathrm{Mg}$ alloys $[34,39,40]$ that result in an anisotropy in properties.

The important result from this investigation is that excellent superplastic ductilities were achieved in the ZK60 alloy when testing HPT-processed materials at different temperatures. This superplastic deformation was achieved due to the ultrafine grain structure achieved after processing by HPT. A maximum ductility with an elongation to failure of $\sim 940 \%$ was achieved at $523 \mathrm{~K}$. Superplastic properties of metallic materials are associated with the length scale and thermal stability of their grain structure. Based on a formal definition 
[41], superplasticity in a polycrystalline material is defined as an elongation of $>400 \%$ in tensile testing while the strain rate sensitivity, $\mathrm{m}$, is close to $\sim 0.5$. All of elongations to failure obtained in these experiments meet the minimum elongation required for superplastic flow. All corresponding appearances of the specimens after pulling to failure in Fig. 5b depict thinned specimens in a reasonable uniform fashion rather than neck initiation. This fracture behavior is characteristic of superplastic flow [42]. The strain rate sensitivity was examined by the strain rate jump test for a range of strain rates including $1.0 \times 10^{-4} \mathrm{~s}^{-1}$ and the results show $\mathrm{m}$ values higher than 0.5 in this range of strain rate. However, lower elongations are observed when pulling similar samples at either higher or lower temperatures.

This very high superplastic behavior after HPT is comparable to the exceptional elongation of $3050 \%$ obtained in a ZK60 alloy with initial grain size of $\sim 0.8 \mu \mathrm{m}$ after processing through two passes of ECAP via route $\mathrm{B}_{\mathrm{C}}$ at $473 \mathrm{~K}$ and testing at $10^{-4} \mathrm{~s}^{-1}$ and $473 \mathrm{~K}$ [43]. The reason for the difference in the magnitude of elongation lies in three different reasons. First, the ECAP tensile samples were cut from billets with gauge lengths of $4 \mathrm{~mm}$ and cross-sectional areas of $3 \times 2 \mathrm{~mm}^{2}$ with regular dimensions whereas the essentially miniature size tensile samples were cut from HPT disks with gauge lengths of $1.0 \mathrm{~mm}$ and gauge cross-sectional areas of only about $1.0 \times 0.64 \mathrm{~mm}^{2}$. Many other investigations reported that miniature specimens will affect measurements of the post-necking elongations in tensile testing [44,45]. Second, the material in this investigation was processed at room temperature and tested in tension at elevated temperatures from 448 to $573 \mathrm{~K}$. This may cause grain growth as the low strain rate tensile tests result in exposure of samples to higher temperatures for at least 3 hours. The annealing experiments showed that grain growth is probable even at the lowest temperature of the experiment. Third, a crystallographic orientation is required to satisfy the Schmid factor. The majority of grains in the microstructure of the samples after ECAP are oriented at $45^{\circ}$ with respect to the tensile axis. However, most of the grains are oriented by $90^{\circ}$ with respect to the tensile axis after HPT. Generally, there are three possibilities of orientation of $c$ axis of basal plane and shear direction [30]. It may be either parallel to, perpendicular to, or taking a defined angle to the shear direction. If the $\mathrm{c}$ axis is parallel to the shear direction, slip on the prismatic $<$ a $>$ or basal $<$ a $>$ planes are less favored since the Schmid factor is zero. If the $\mathrm{c}$ axis is perpendicular to the shear direction, easy slip occurs on the prismatic planes as in the behavior of ECAP-processed samples in tensile testing. If the $\mathrm{c}$ axis is oriented in a random angle to the shear direction, it is possible for both prismatic $<\mathrm{a}>$ and pyramidal $<\mathrm{c}+\mathrm{a}>$ slip to be activated. Thus, there is a general consistency between the superplastic results on the ZK60 specimens processed by HPT in the present investigation and the ZK60 specimens processed earlier by ECAP [43] although an identical comparison is not possible because of these limitations.

The unusual high ductility at low testing temperature of $448 \mathrm{~K}\left(0.49 T_{m}\right)$ was noticed for the tested material and it suggests the importance of the bimodal grain structure in enhancing superplasticity of ultrafine-grained $\mathrm{Mg}$ alloys. Evidence of a bimodal microstructure is apparent in TEM observations and EBSD results in Figs 1,2 and 3. After processing by HPT at room temperature, the microstructure is now bimodal with some relatively large grains having sizes of $\sim 1.2 \pm 0.2 \mu \mathrm{m}$ surrounded by arrays of relatively smaller grains of $\sim 250 \pm 50 \mathrm{~nm}$. Considering there are only limited restoration processes at temperatures below $0.5 T_{m}$, optical observations revealed that no significant alteration in grain size distribution occurred after static annealing of about 3 hours. A number of studies reported excellent superplastic behavior of SPD ZK60 as a result of a bimodal grain structure $[46,47]$ with larger grains of $\sim 4 \mu \mathrm{m}$ and submicrometer grains of $\sim 0.4 \mu \mathrm{m}$. It was suggested that the bimodal grain structure promotes superplastic flow [48]. Superplasticity is driven by a grain boundary sliding (GBS) mechanism [49] and the GBS is combined with some limited intragranular slip [50]. Therefore the bimodal structure can facilitate the flow more readily considering that generating and accommodating slip and twinning is easier in larger grains.

\section{Summary and conclusions}

1. Successful grain refinement of ZK60 alloy was obtained with a grain size of $\sim 700 \mathrm{~nm}$ after processing by HPT through a total of 5 turns at room temperature and pressure of 2.0 $\mathrm{GPa}$.

2. Vickers microhardness measurements showed reasonable homogeneity after processing by HPT with a enhancement of hardness to a value of $\mathrm{Hv} \approx 124$. Additional annealing at $448 \mathrm{~K}$ for 40 hours maintained the homogeneity of microhardness across the disks but with a decrease in hardness to $\mathrm{Hv} \approx 85$ due to a restoration of microstructure.

3. Excellent superplastic behavior was achieved in tensile testing of samples processed by HPT at different temperatures. A maximum elongation of about $\sim 940 \%$ at 523 $\mathrm{K}$ was obtained when testing with an initial strain rate of $1.0 \times 10^{-4} \mathrm{~s}^{-1}$.

4. An unusual enhancement of superplastic behavior with a maximum elongation of about $\sim 660 \%$ was obtained at a testing temperature of $448 \mathrm{~K}$ owing to a bimodal structure. The stability of the bimodal structure at lower temperatures assisted the microstructure to accommodate grain boundary sliding and intragranular slip simultaneously and prevent necking. This gave an improvement in the elongation to failure.

Acknowledgements. This work was supported in part by the National Science Foundation of the United States under Grant No. DMR-1160966 and in part by the European Research Council under ERC Grant Agreement No. 267464-SPDMETALS.

\section{References}

1. M. Kawasaki, R. B. Figueiredo, T. G. Langdon, J. Mater. Sci. 47, 7719 (2012).

2. E. O. Hall, J. Proc. Phys. Soc. B 64, 747 (1951).

3. N. J. Petch, J. Iron Steel Inst. 174, 25 (1953).

4. T. G. Langdon, Acta Mater. 61, 7035 (2013). 
5. R.Z. Valiev, R. K. Islamgaliev, I. V. Alexandrov, Prog. Mater. Sci. 45, 103 (2000).

6. R.Z. Valiev, Y. Estrin, Z. Horita, T.G. Langdon, M. J. Zehetbauer, Y. T. Zhu, JOM 58 (4), 33 (2006).

7. R.Z. Valiev, R.S. Musalimov, N.K. Tsenev, Phys. Status Solidi. 115 A, 451 (1989).

8. S. V. Divinski, G. Reglitz, H. Rősner, Y. Estrin, G. Wilde, Acta Mater. 59, 1974 (2011).

9. G. W. Nieman, J.R. Weertman, R. W. Siegel, Scr. Metall. 24, 145 (1990).

10. R.Z. Valiev, R.S. Musalimov, O.A. Kaibyshev, R. I. Kuznetsov, N. K. Tsenev, Proc. U. S.S. R. Acad. Sci. 301, 864 (1988).

11. Y. Zhu, R.Z. Valiev, T. G. Langdon, N. Tsuji, K. Lu, MRS Bull. 35, 977 (2010).

12. R.Z. Valiev, T.G. Langdon, Prog. Mater. Sci. 51, 881 (2006).

13. A.P. Zhilyaev, T.G. Langdon, Prog. Mater. Sci. 53, 893 (2008).

14. B. Mordike, T. Ebert, Mater. Sci. Eng. A 302, 37 (2001).

15. Y. Huang, R. B. Figueiredo, T. G. Langdon, Rev. Adv. Mater. Sci. 31, 129 (2012).

16. R. B. Figueiredo, T.G. Langdon, J. Mater. Sci. 44, 4758 (2009).

17. S. A. Torbati-Sarraf, T. G. Langdon, J. Alloy Compd. 613, 357 (2014).

18. S. A. Torbati-Sarraf, T. G. Langdon, Adv. Mater. Res. 922, 767 (2014).

19. Y. Harai, M. Kai, K. Kaneko, Z. Horita, T. G. Langdon, Mater. Trans. 49, 76 (2008).

20. S. Sabbaghianrad, T. G. Langdon, Mater. Sci. Eng. A 596, 52 (2014).

21. M.P. Staiger, A.M. Pietak, J. Huadmai, G. Dias, Biomaterials 27, 1728 (2006).

22. F. H. Froes, D. Eliezer, E. Aghion, JOM 50 (9), 30 (1998).

23. K. Johnson, Adv. Mater. Proc. 160, 62 (2002).

24. A. A. Luo, Int. Mater. Rev. 49, 13 (2004).

25. S. A. Torbati-Sarraf, R. Mahmudi, Int. J. Mod. Phys. Conf. Ser. 05, 307 (2012).

26. D. R. Nugmanov, R. K. Islamgaliev, Rev. Adv. Mater. Sci. 31, 157 (2012).

27. S. C. Yoon, Z. Horita, H. S. Kim, J. Mater. Process. Technol. 201, 32 (2008).

28. R. B. Figueiredo, P.H. R. Pereira, M.T. P. Aguilar, P. R. Cetlin, T. G. Langdon, Acta. Mater. 60, 3190 (2012).
29. M. Kai, Z. Horita, T. G. Langdon, Mater. Sci. Eng. A 488, 117 (2008).

30. Y. Huang, R. B. Figueiredo, T. Baudin, A.L. Helbert, F. Brisset,, T. G. Langdon, J. Mater. Sci. 47, 7796 (2012).

31. H. Jiang, Y. T. Zhu, D. P. Butt, I. V. Alexandrov, T. C. Lowe, Mater. Sci. Eng. A 290, 128 (2000).

32. H. K. Kim, W. J. Kim, Mater. Sci. Eng. A 385, 300 (2004).

33. In: ASM Handbook, Materials Park, OH: ASM International Vol 2, (1990).

34. X. G. Qiao, Y. W. Zhao, W. M. Gan, Y. Cheng, M. Y. Zheng, K. Wu, N. Gao, M. J. Starink, Mater. Sci. Eng. A 619, 95 (2014).

35. S. A. Torbati-Sarraf, R. Mahmudi, Mater. Sci. Eng. A627, 3515 (2010).

36. E. Kelly, W. F. Hosford, Trans. Metall. Soc. AIME 242, 5 (1968).

37. F. J. Humphreys, M. Hatherly, Recrystallization and Related Annealing Phenomena, Elsevier, Oxford, United Kingdom, (1996).

38. J. Čížek, I. Procházka, B. Smola, I. Stulíková, R. Kužel, Z. Matěj, V. Cherkaska, R. K. Islamgaliev, O. Kulyasova, Mater. Sci. Eng. A 462, 121 (2007).

39. W. J. Kim, H. T. Jeong, Mater. Trans. 46, 251 (2005).

40. D. R. Nugmanov, R. K. Islamgaliev, Rev. Adv. Mater. Sci. 31, 157 (2012).

41. T. G. Langdon, J. Mater. Sci. 44, 5998 (2009).

42. T. G. Langdon, Metal. Sci. 16, 176 (1982).

43. R. B. Figueiredo, T. G. Langdon, Adv. Eng. Mater. 10, 37 (2008).

44. Y.H. Zhao, Y.Z. Guo, Q. Wei, A. M. Dangelewicz, C. Xu, Y. T. Zhu, T. G. Langdon, Y.Z. Zhou, E. J. Lavernia, Scripta. Mater. 59, 627 (2008).

45. Y.H. Zhao, Y.Z. Guo, Q. Wei, T.D. Topping, A. M. Dangelewicz, Y. T. Zhu, T. G. Langdon, E. J. Lavernia, Mater. Sci. Eng. A 525, 68 (2009).

46. R. Lapovok, R. Cottam, P. F. Thomson, Y. Estrin, J. Mater. Res. 20, 1375 (2005).

47. R. Lapovok, P. F. Thomson, R. Cottam, Y. Estrin, Mater. Sci. Eng. A 410-11, 390 (2005).

48. R. Lapovok, Y. Estrin, M.V. Popov, T. G. Langdon Adv. Eng. Mater. 10 (5), 429 (2008).

49. T. G. Langdon, Mater. Sci. Eng. A174, 225 (1994).

50. R. Z. Valiev, T. G. Langdon, Acta Metall. Mater. 41, 949 (1993). 